\title{
El entramado cultural de la militancia revolucionaria en el Partido Revolucionario de los Trabajadores-Ejército Revolucionario del Pueblo y Montoneros de la Argentina en los setenta
}

The cultural dimension of revolutionary militancy. An approach to the experience of the Revolutionary Workers Party-Revolutionary People's Army and the Montoneros in Argentina in the seventies

\section{María Olga Ruiz ${ }^{*}$}

Resumen: El artículo analiza la dimensión cultural de la militancia revolucionaria en la Argentina de los sesenta y setenta, puntualmente los casos de Montoneros y el PRT-ERP. Estas organizaciones construyeron modelos identitarios entrelazando la vida cotidiana de sus militantes con definiciones político-ideológicas específicas. La militancia involucraba todas las dimensiones de la vida; de ahí la necesidad de "enmarcar" las conductas cotidianas a través del establecimiento de normas y patrones de conducta bien definidos.

Palabras Clave: Revolución, Disciplina, Cultura política, Vida cotidiana, Militancia.

\begin{abstract}
The article analyzes the cultural dimension of revolutionary militancy in the Argentina of the sixties and seventies, specifically Montoneros and the PRT-ERP cases. These organizations built identity models combining everyday life of its members with political and ideological specific definitions. Militancy involved all dimensions of life; therefore the need to "frame" the daily behavior through the establishment of norms and standards of welldefined behavior
\end{abstract}

Key Words: Revolution, Discipline, Political culture, Daily life, Militancy

\footnotetext{
* Chilena, Dra. en Estudios Latinoamericanos, Universidad de La Frontera, Núcleo Científico de Ciencias Sociales y Humanidades. Este trabajo es parte del proyecto de investigación postdoctoral titulado "Traicionar la revolución. La traición política en el PRT-ERP y Montoneros de la Argentina, el MIR de Chile y el MLN-T de Uruguay" (Proyecto FONDECYT 3150169) y recoge algunos de los resultados obtenidos en la investigación doctoral titulada: María Olga Ruiz, Historias y memorias de traición. Subjetividad revolucionaria, mandatos militantes y traición en el Partido Revolucionario de los Trabajadores-Ejército Revolucionario del Pueblo (PRT-ERP), Montoneros y el Movimiento de Izquierda Revolucionaria (MIR) en las décadas del sesenta y setenta". olga.ruiz@ufrontera.cl
} 


\section{Introducción}

El presente artículo analiza la dimensión subjetiva y cultural de las militancias de los sesenta y setenta en la Argentina, puntualmente los casos de Montoneros y el PRT-ERP, poniendo atención en las lógicas de acción, los discursos, las percepciones e imágenes que los militantes poseían sobre los otros y sobre la propia comunidad o grupo de pertenencia, así como los deseos, anhelos y certezas que los movilizaban. ${ }^{1}$

Ambas organizaciones son parte de la llamada Nueva Izquierda Revolucionaria (en adelante NIR) conosureña, corriente que involucra a organizaciones marxistas y no marxistas ${ }^{2}$. Como bien señala la socióloga argentina María Cristina Tortti, en la Argentina, el progresivo deslizamiento hacia posicionamientos radicales involucró a una amplia gama de tradiciones políticas, incluido el peronismo y sectores católicos que abrazaron la promesa de la revolución socialista. El surgimiento de la NIR se dio en el marco de una expansión de la protesta social y una eclosión de movimientos insurreccionales, en la que las organizaciones armadas fueron la expresión más radical -pero no la única- de un proceso que convocó a actores diversos y de múltiples tradiciones políticas, sociales e ideológicas.

La corriente identificada como "Nueva izquierda revolucionaria" refiere, en términos muy amplios, a las organizaciones políticas que abrazaron la promesa revolucionaria bajo la impronta de la experiencia cubana. Pese a la enorme diversidad que la caracteriza, existen rasgos básicos que permiten hablar de la NIR como un conjunto, estos son: su proyecto de transformación radical de la sociedad y su definición por oposición a la izquierda tradicional $^{3}$. Justamente, más allá de sus diferencias, las organizaciones identificadas como parte de la NIR comparten un núcleo articulador: la oposición a los partidos comunistas y socialistas, a los que se acusaba de carecer de una auténtica práctica revolucionaria por encontrarse atrapados en una dinámica burocratizada que desviaba la energía histórica de los sectores populares hacia el reformismo. En esa dirección, las organizaciones de la NIR se proponían desenmascarar lo que consideraban como la naturaleza reformista de la izquierda tradicional, definiéndose a sí mismas como las portadoras del verdadero proyecto revolucionario. Así, los jóvenes revolucionarios interpelaron a los partidos tradicionales y les exigieron definiciones, pues, desde su perspectiva, el momento histórico no admitía ambigüedades.

1 Norbert Lechner, Los Patios interiores de la Democracia: Subjetividad y Política, (Santiago: FLACSO, 1988)

2 María Cristina Tortti, "La nueva historia en la historia reciente de Argentina", Revista de Estudios Sociales № 3 (La Plata: Prometeo, 2005).

3 Tortti, 57. 
La voluntad de disputar el liderazgo a la izquierda tradicional bipartidista estaba acompañada de una desconfianza radical hacia el conjunto del sistema político que se intentaba erradicar. Tal como señala el investigador Eduardo Rey Tristán,

"Era el caso del Estado, que se veía como garante de la reproducción del sistema; el Derecho, que institucionalizaba la explotación de las mayorías y dirimía los conflictos de las élites, los Partidos, como parte del sistema político seguían el juego de las clases dominantes, o la Democracia y la Libertad, categorías instrumentales en las que no coincidían explotados y explotadores; la democracia de unos no era la de los otros, y la libertad de los segundos era la carencia de los primeros". ${ }^{4}$

Por su parte, Michael Lowy ${ }^{5}$ sostiene que un rasgo característico de la NIR fue su voluntarismo revolucionario, el que, en su opinión, se oponía al determinismo pasivo y fatalista de la izquierda tradicional. Para estas organizaciones, la voluntad, el coraje y la presencia de una vanguardia revolucionaria, eran la fórmula que aseguraría el triunfo del socialismo, éxito que no se ponía en cuestión y cuya certeza descansaba en un "análisis científico" de la historia. Tal como había señalado Guevara, "cuando los pueblos se deciden a vencer o morir y los encabeza una dirección lúcida, audaz, firme, el fruto de su determinación es siempre la victoria",

En términos metodológicos y con el objeto de analizar la experiencia militante de las dos organizaciones señaladas, he analizado bibliografía especializada acerca de la historia política de ambos grupos, documentos internos y prensa partidaria, tesis universitarias y testimonios orales y escritos de ex integrantes del PRT-ERP y Montoneros ${ }^{7}$. En este sentido, este trabajo articula el análisis histórico con la categoría de memoria social y, por lo tanto, se inscribe dentro de dos campos de investigación que están estrechamente vinculados: la historia reciente y los estudios de la memoria social.

En líneas muy generales, es posible identificar dos formas de concebir la relación entre historia y memoria. Mientras la primera las observa como categorías opuestas y excluyentes (la historia como sinónimo de verdad científica y la memoria como ficción), en

\footnotetext{
$4 \quad$ Michael Lowy, El marxismo en América Latina, Santiago (Santiago: Lom, 2007:61)

5 Lowy, 49.

6 Ernesto Guevara, "Declaración general de la Primera Conferencia Latinoamericana de Solidaridad", Primera Conferencia de la OLAS (La Habana: Ediciones El orientador revolucionario, 1967: 69).

${ }^{7}$ Se han consultado los testimonios producidos por Memoria Abierta, organismo de la sociedad civil que se propone preservar y difundir material documental sobre el terrorismo de Estado en Argentina. A partir del año 2001 puso en marcha la producción de testimonios sobre la vida social y política de los años sesenta y setenta. Un número significativo de ese material (370 de un total de 700) corresponde a militantes sociales y políticos de esa época. Este material está registrado en formato audiovisual y se encuentra abierto al público.
} 
la segunda se asimilan ambas categorías, afirmando que las dos son construcciones mitificadas. Lejos de estas miradas, en esta tesis asumo que tanto la historia como la memoria son formas de representación -y no restitución- del pasado y que entre ellas hay una relación de mutua interpelación que no pone en cuestión sus especificidades. Por un lado, la historia (entendida acá como historiografía) intenta preservar una forma de conocimiento del pasado verificable y transmisible; por lo mismo, es sistemática (o aspira a serlo) y está movilizada por la pretensión de la veracidad. Posee, asimismo, sus propios mecanismos de legitimación y espacios de circulación y responde a reglas de una disciplina, siendo sometida al juicio crítico de una comunidad académica. Por su parte, la memoria se construye a partir de la subjetividad de los sujetos y opera como atribución de sentidos y significados, es decir, atiende no a los hechos efectivamente sucedidos sino al modo en que se recuerdan. No hay, por lo tanto, memorias falsas ni verdaderas. ¿Cómo articular ambas categorías? Usando la memoria para el análisis histórico sin someterse a ella; valorando el brillo singular de la subjetividad pero situándola en un marco de comprensión general más amplio; desde una actitud crítica, aplicando criterios de verificación; poniendo en diálogo ciertas memorias con otras y también con documentos, identificando sus falacias y distorsiones ${ }^{8}$.

\section{I.}

El cientista político chileno-alemán Norbert Lechner ${ }^{9}$, sostiene que la política posee una dimensión simbólica y subjetiva, de modo que la experiencia política y en este caso, la militancia revolucionaria, nos remite a un mundo común, a un espacio en el que los sujetos reafirman su pertenencia a un colectivo que los antecede y trasciende. Esta perspectiva de análisis pone atención no solo a las acciones políticas, a lo que se hizo o se dejó de hacer, si no también a las orientaciones que guiaron esas acciones, a los modos en que se emprendieron y los marcos valóricos y emocionales en que se desplegaron.

Las nociones de "subjetividad política" y "cultura política" propuestas por el ya mencionado Lechner y otros autores como Fabio López de la Roche ${ }^{10}$, permiten explorar la interacción entre ambas esferas de la realidad social, iluminando aspectos que otros enfoques han desatendido. Por su parte, la historiadora chilena Cristina Moyano, entiende que la cultura política permite analizar:

8 Enzo Traverso, El pasado, instrucciones de uso. Historia, memoria, política (Madrid: Editorial Marcial Pons, 2007) 24.

9 Norbert Lechner, La Conflictiva y nunca acabada construcción del orden deseado (Madrid: Siglo XXI, 1986).

${ }^{10}$ López de la Roche, F., "Aproximaciones al concepto de cultura política", Convergencia 7, (México: 2000: 93-123) 
"la significación que (las personas) realizan de su actuación; las luchas por la búsqueda de las hegemonías del recuerdo y del presente; la direccionalidad que le entregan a la acción y las lecturas que hacen de ella, y las redes sociales que articulan sus relaciones; en suma, la construcción de una identidad partidaria forjada en la vida cotidiana misma"

En esta misma línea argumentativa, pero ahora desde el campo de los Estudios Culturales, resultan pertinentes los planteos de Raymond Williams, quien señala que las ideas son sentidas de un modo particular y, asimismo, los sentimientos y emociones están articulados con ideas que han sido formuladas en forma organizada y sistemática. De este modo, la militancia política es una forma de vivir, comprender y sentir la realidad, y supera con creces la mera adscripción a un proyecto político y/o ideológico. ${ }^{12}$ Es preciso recordar que el trabajo de Williams es parte de una corriente intelectual en la que destacan las figuras del crítico literario Richard Hoggarth y del historiador Edward P. Thompson, quienes desde el Center for Contemporary Cultural Studies, de la Universidad de Birmingham, realizaron una aguda crítica al marxismo más ortodoxo y al modo en que los enfoques economicistas comprendían la cultura, esto es, subordinada a los modos y a las relaciones de producción. Lejos de esta mirada, desde los Estudios Culturales se propone que todo, incluso la economía y la política, está permeado por la cultura ya que todo sucede dentro de ella.

En relación al caso argentino, el investigador Horacio Tarcus señala que las organizaciones políticas marxistas deben ser analizadas no solo en la dimensión declarativa y explícita sino también considerando sus dinámicas reales, los modos en que sus militantes son reclutados y promovidos y las formas en que se produce el discurso oficial. Asimismo, afirma este autor que no basta con estudiar el nivel racional y consciente de la acción política, que se manifiesta en programa, estatutos, declaraciones, sino también el plano de los imaginarios, el que actúa y tiene un impacto en el primero.

Tarcus propone que independiente de que una organización política se declare laica y racionalista, en la práctica puede reproducir elementos que son propios de una secta política, entendida ésta como una forma "parcialmente secularizada" de la secta religiosa. Así, se ponen en marcha dinámicas que pasan desapercibidas y son naturalizadas por sus militantes, por ejemplo: asignar un rol decisivo a ritos y ceremonias, promover la disolución del individuo en el colectivo, establecer una división tajante entre el "afuera" y el "adentro", instaurar una rígida estratificación interna, promover un culto al líder e instalar la figura del desertor y el traidor.

\footnotetext{
${ }^{11}$ Moyano Barahona, C. El MAPU durante la Dictadura. Saberes y prácticas políticas para una microhistoria de la renovación socialista en Chile 1973-1989. (Santiago: Ediciones Universidad Alberto Hurtado, 2010) 42. 12 Raymond Williams, Marxismo y literatura (Buenos Aires: Editorial Las Cuarenta, 2009).
} 

dimension of revolutionary militancy. An approach to the experience of the Revolutionary Workers PartyRevolutionary People's Army and the Montoneros in Argentina in the seventies, Revista Izquierdas $\mathrm{N}^{\circ} 25$, Octubre 2015, IDEA-USACH, ISSN 0718-5049, pp. 29-53

Estas dinámicas expresan - y ésta es la principal tesis del autor- la pervivencia de lo sagrado en la política cuestión que involucra aún a organizaciones marxistas que se piensan a sí mismas en términos racionalistas. Por esta razón, señala, "es necesario aceptar que lo religioso sobrevive en la política más de lo que tiempo atrás los marxistas estábamos dispuestos a aceptar"13.

Las organizaciones que acá examinamos construyeron modelos identitarios entrelazando la vida cotidiana de sus militantes con definiciones político-ideológicas específicas. De este modo, la militancia involucraba todas las dimensiones de la vida; de ahí la necesidad de "enmarcar" las conductas cotidianas a través del establecimiento de normas y patrones de conducta $^{14}$. Es preciso considerar que el PRT-ERP y Montoneros eran organizaciones clandestinas que debieron enfrentar tempranamente la represión y la persecución política, lo que incidió en la formación de culturas partidarias que se organizaban en torno a pautas y códigos de comportamiento bien definidos. Como es razonable, el apego a esos mandatos fue considerado crucial para asegurar la continuidad -si no la supervivencia- de las mismas organizaciones, lo que explica el alto grado de adhesión de parte de la militancia a esas normativas.

La práctica cotidiana de la militancia fue diversa y en esa pluralidad incidían variados elementos, sin embargo, es posible señalar que el ingreso a estas organizaciones supuso un giro radical en la vida de sus militantes, puesto que, tal como plantea Alejandra Oberti,

\begin{abstract}
"la militancia representa (...) una nueva forma de relacionarse con el mundo y con sus pares, incluso en aquellos casos en que en las familias de origen está presente la política, ya sea en discusiones y debates o a través de participación activa. La certeza de que 'la hora las llamaba' y que no había otro camino a recorrer que no fuera el del compromiso está presente en numerosos testimonios. Una vez instaladas en el espacio de la política, una vez tomada la decisión de ingresar a las diferentes organizaciones, los tiempos se aceleraban y todo se transformaba en un vértigo donde había muy poco lugar para reflexionar acerca de las prácticas..."15.
\end{abstract}

\footnotetext{
${ }^{13}$ Tarcus, Horacio, "La secta política Ensayo acerca de la pervivencia de lo sagrado en la modernidad", Revista El Rodaballo Vol. 9. (Buenos Aires, 1998/1999) 22.

14 Alejandra Oberti, "Género, política y violencia. Vida cotidiana y militancia en las décadas del sesenta y setenta". Tesis para optar por el título de Doctora de la Universidad de Buenos Aires en Ciencias Sociales, Facultad de Ciencias Sociales (UBA: Mimeo inédito, 2011).
}

15 Oberti, 142. 
El presente análisis considera las características específicas de cada organización y al mismo tiempo, los rasgos que comparten y que son comunes a todos los partidos y/o movimientos que abrazaron la causa revolucionaria, pues tal como advierte la ex militante montonera Adriana Robles en relación a los jóvenes militantes de su generación:

"Veo tantas coincidencias entre nosotros..., personas que nunca nos conocimos hemos transitado por los mismos lugares, leído los mismos libros, cantado las mismas canciones, gozado las mismas alegrías y compartido los mismos peligros. Nos unía el ansia de justicia y revolución social. Nos unía la esperanza del Hombre Nuevo",

\section{II.}

De acuerdo al historiador Eduardo Devés ${ }^{17}$, los años sesenta comienzan con la Revolución Cubana y terminan a inicios de los años setenta, con la oleada de golpes militares en el Cono Sur latinoamericano. Este período estuvo marcado por el ideal de la transformación que, ya sea en su versión reformista o revolucionaria, se apoyaba en una amplia gama de propuestas teóricas que respaldaban el deseo y la urgencia de un cambio en las estructuras sociales. Fue el momento, además, en que la opción por las armas se instaló con fuerza en sectores cada vez más amplios. Los hechos que ocurrían en el mundo y en la propia América Latina parecían confirmar que la lucha revolucionaria era tan justa como necesaria, y que el triunfo de los dominados era cercano e inevitable.

Por otro lado, los sesenta y setenta fueron el escenario de significativas modificaciones en la vida cotidiana de hombres y mujeres, de modo que las relaciones familiares, de pareja y las pautas de comportamiento sexual se vieron alteradas al calor de las transformaciones sociales y políticas. Lo que Eric Hobsbawm ${ }^{18}$ denominó revolución cultural, para referirse al proceso mundial que modificó las pautas sociales en el plano moral, sexual y familiar, tuvo una expresión local que se ajustó a la realidad conosureña. De acuerdo a Isabella Cosse $^{19}$, en la Argentina esta revolución fue más bien discreta, ya que si bien hubo fisuras en los modelos familiares y en las pautas sexuales predominantes desde los años cincuenta, el modelo heterosexual, la asociación entre sexualidad y amor romántico y las

16 Adriana Robles, Perejiles. Los otros Montoneros, (Buenos Aires, Colihue, 2005) 31.

17 Devés Valdés, Eduardo, El pensamiento latinoamericano en el siglo XX. Desde la CEPAL al neoliberalismo (1950-1990) (Santiago: Biblos, 2003).

18 Hobsbawm, Eric, Historia del Siglo XX, (Buenos Aires: Planeta/Crítica, 2002).

19 Cosse, Isabella, Pareja, sexualidad y familia en los años sesenta (Buenos Aires, Siglo Veintiuno Editores, 2010). 
desigualdades de género en materia de moral sexual, se mantuvieron intactos. Lo cierto es que la disminución de la tasa de natalidad y el mayor acceso a la educación universitaria fueron elementos a considerar al momento de analizar las causas que llevaron a un número significativo de mujeres jóvenes a sumarse a las organizaciones político-militares. Un acontecimiento crucial en estas transformaciones fue la difusión de la anticoncepción oral, la que permitió a las mujeres regular su fecundidad y muchas veces postergarla en función de su desarrollo en otras áreas, como la política. La conquista de mayores niveles de autonomía sobre sus cuerpos en particular, y sobre sus vidas en general, explica en parte la significativa participación femenina en diversas organizaciones y movimientos políticos.

Muchos de quienes se integraron a las organizaciones acá analizadas lo hicieron movilizados por un ánimo crítico que se nutría de las transformaciones sociales, políticas y culturales que ocurrían en su entorno. Como señala Adriana Robles,

"Nadie escapaba al fervor social que corría como un río desbocado por toda la Argentina (...) Y no se podía eludir. Mi rebeldía pasaba no solo por los cuestionamientos a casi todo lo establecido, por leer el diario Noticias en las horas de Matemáticas o por hacer terribles declaraciones públicas en la pizarra del aula (como cuando escribí un homenaje a los muertos de Trelew para horror de algunas y desorientación de otras) sino también por modificar de manera desafiante el estricto uniforme escolar: el suéter azul marino obligatorio se convertía en un pulóver turquesa; los mocasines negros en botitas de gamuza; el pelo recogido en pelo suelto, la corbata desaparecía bajo colgantes de todo tipo ${ }^{20,}$.

Esos pequeños desacatos cotidianos, que incluían desde la lectura de prensa revolucionaria hasta la puesta en escena de una corporalidad distinta, expresaban un malestar social generalizado que se tradujo en una intensificación de la protesta social y una radicalización política que convocó a amplios sectores de la sociedad.

Socorro Alonso, ex militante del PRT-ERP, se refiere al escenario argentino de fines de los sesenta, durante la dictadura de Onganía:

"en aquel momento se llevaban a la gente porque tenía el pelo largo o porque cantaban y tocaban la guitarra; era normal e incesante que a la gente se la persiguiera por motivos artísticos y culturales, no solamente políticos, y yo forme parte de esa generación y también sentí deseos de romper con todo...Una hermana siete años mayor que yo no lo hizo y se crio con la otra cultura (...) la de los vestidos de largo, eso era como el pasado... a partir de nuestra generación fue como el pasado. Nosotros rompimos con todo eso y hacíamos el

20 Robles, 38. 

dimension of revolutionary militancy. An approach to the experience of the Revolutionary Workers PartyRevolutionary People's Army and the Montoneros in Argentina in the seventies, Revista Izquierdas $\mathrm{N}^{\circ} 25$, Octubre 2015, IDEA-USACH, ISSN 0718-5049, pp. 29-53

amor antes de casarnos y antes no era eso, sino que las chicas tenían que llegar vírgenes al matrimonio. Digo esto porque fue realmente romper con todo...fue toda una revolución que se dio, en lo cultural, en lo social"21.

Tal como advierte la ex militante, la ruptura desplegada era tan política como cultural y ponía en juego una nueva temporalidad; inscribía en el pasado todo aquello que se rechazaba y debía ser superado; la ruptura era fundante e inauguraba un presente de lucha, anunciando un futuro cargado de promesas.

En el caso de Montoneros, muchos militantes ingresan a estas organizaciones luego de participar en comunidades religiosas influenciadas por las propuestas de la Teología de la Liberación. Adriana Robles, ex montonera, recuerda:

"Con Joaquín comenzamos a entender el compromiso entre la religión y la política. A partir de él comenzamos a crecer en nuestra militancia que, de ser una actividad solo religiosa, comenzó a expandirse hacia el plano social para terminar en muchos de nosotros con un firme compromiso político con el peronismo revolucionario. Porque como se decía en ese momento, el deber de todo cristiano era hacer la revolución ",22.

Ahora bien, las organizaciones políticas debían encuadrar y disciplinar el ánimo contestatario de quienes ingresaban a sus filas. Para ello, se desplegaron actividades de formación y se pusieron en marcha iniciativas para dar uniformidad al cuerpo partidario. Había que transformar a los jóvenes rebeldes en militantes bien disciplinados y en cuadros políticos profesionales.

En relación a la experiencia perretista, Roberto Santucho afirmó que el V Congreso del PRT fue un momento decisivo en la historia de la organización. A partir de esa instancia, el Partido logró: a) desembarazarse de los elementos no proletarios que hasta entonces ocupaban un lugar importante en la Dirección; b) establecer una estructura nacional de cuadros sólidos; c) reorganizarse en torno a los principios del marxismo-leninismo; d) dar origen al Ejército Revolucionario del Pueblo.

Esos avances daban cuenta del inicio de una nueva etapa en la que la organización se lanzó con decisión al cumplimiento de las que consideraba sus obligaciones revolucionarias. Al año siguiente, en marzo de 1971, el Comité Central señalaba en sus resoluciones, que era indispensable fortalecer a la organización con el objeto de que alcanzara un papel hegemónico en la vanguardia obrera, estudiantil y popular. Los logros alcanzados a partir del V Congreso y la puesta en marcha del Primer Plan Operativo Militar, habían logrado

21 Testimonio de María del Socorro Alonso, Memoria Abierta, Buenos Aires, 2001. El destacado es mío. 22 Robles, 22. 
que el Partido lograra visibilidad y prestigio en el pueblo. Para ello, era indispensable poner en práctica medidas tendientes a disciplinar y homogenizar a la militancia. Tal como señalan los acuerdos del Comité Central de marzo de 1971:

"Nada se puede hacer sino contamos con células fuertes y homogéneas, constituidas por profesionales de la revolución, por compañeros entregados en alma y vida a la lucha revolucionaria, por elementos preparados política, militar y moralmente. Células fuertes disciplinadas, dedicadas a la lucha y al estudio, homogéneas, serán las escuelas fundamentales en que nuestro Partido forjará millares de revolucionarios..."23,

Tiempo después, el tema disciplinario volvía aparecer como un aspecto central que debía ser mejorado. Luego de un periodo marcado por el crecimiento partidario, existía preocupación por lo que se consideraba un déficit en la formación de los cuadros dirigentes.

Para ello, se consideró necesario fortalecer la formación ideológica de los cuadros, de modo que en septiembre de 1973 se votó un plan de acción que consideraba el estudio de textos de los clásicos marxistas, especialmente las obras de Lenin. De acuerdo al historiador Pablo Pozzi, esta política llegó tarde, pues para esa fecha los militantes estaban sumergidos en la vorágine del activismo y al mismo tiempo, habían hecho propias las tendencias anti-intelectuales que caracterizaban a la cultura perretista. Señala este autor:

“...el PRT-ERP orientó permanentemente a sus militantes hacia el estudio y se esforzó por organizar escuelas que elevaran la formación de ésos. Pero así como sus cuadros podían revelarse muy creativos en resolver un problema concreto, a la hora de formarse en el marxismo se mostraban increíblemente rígidos repitiendo conceptos que eran comprendidos a medias" 24 .

Lo cierto es que el anti-intelectualismo perretista se expresaba en el valor que se le asignaba a "lo concreto" por sobre la discusión teórica e ideológica. Quizás por esta misma razón, y tal como advierte el ex dirigente Luis Mattini, en la organización se asociaba la labor intelectual al campo de las Artes, las Humanidades y las Ciencias Sociales, áreas que eran subvaloradas. Por el contrario, existía "un enorme respeto por las ciencias, un respeto casi religioso el cual se aproximaba más al positivismo que al marxismo y esto se ponía en

23 "Resoluciones del Comité central de marzo de 1971", A vencer o morir. PRT-ERP documentos. Daniel De Santis, (Buenos Aires: Eudeba, 1998) 205.

24 Pablo Pozzi, Por las sendas argentinas..." El PRT-ERP, la guerrilla marxista (Buenos Aires: Ediciones Imago Mundi, 2004) 105. 
evidencia cuando se encaraban complicadas construcciones de infraestructura pensando que con un arquitecto el problema estaba resuelto...."25.

En relación a la disciplina partidaria y las posibilidades de disentir o cuestionar las órdenes emanadas desde la dirección política, Zenón Sánchez, militante del PRT-ERP, recuerda:

"Ya se había constituido la dirección del PRT en la fábrica, (...) yo estaba en desacuerdo con una postura y tenía que ir a defenderla públicamente por simple disciplina partidaria... Cuando habíamos ganado el sindicato, llega una orden de arriba que había que intensificar la lucha armada que para elevar el nivel de combatividad y experiencia de los compañeros, aquí había que hacer una cosa grande... y ¿cuál era eso?: matar a Acevedo. Bueno vamos nosotros al comité fabril del partido, a discutir en presencia de un miembro del Buró político, y lo que yo veo es que nos querían comprometer a votar una decisión de alto vuelo para hacernos sentir que nosotros éramos lo que habíamos hecho esto (...) Entonces se expone que Acevedo es un hijo de puta, se dibuja la vida personal de este individuo que es despreciable... y lo tenemos que matar y es cierto, lo tenemos que matar... pero no, no conviene políticamente, lo que hay que hacer es denunciar a este hijo de puta porque si lo matamos a él van a venir cien como él a reemplazarlo, peor que él y nosotros no podemos -decía yo- cambiar a este hijo de puta por todos nuestros compañeros que son buenos, porque nosotros lo tocamos a este y nos limpian desde pichi hasta el último militante (...) Y este no es un problema de ser corajudo o de miedo... yo me opuse abiertamente y vamos a tres rondas de votación y yo renuncio, yo no estoy de acuerdo con este crimen, no por este hijo de puta que yo estoy de acuerdo que tiene que morir, pero no así y yo no lo voy a cambiar por mis compañeros, yo no voy a hacer cómplice de eso (...) los otros compañeros por disciplina o por menos nivel político, aceptaban. (...)"26.

En este caso, el militante no cuestionaba la ejecución en términos morales ("yo estoy de acuerdo que tiene que morir"), sino la pertinencia política de esa decisión. Aclara, al mismo tiempo, que su rechazo no se debía a falta de coraje o miedo, sino a la inutilidad política de la orden. Señala también que sus otros compañeros aceptaban, no necesariamente por convencimiento, sino por disciplina o por no tener el nivel político suficiente como para criticar abiertamente un mandato de los dirigentes. Lo cierto es que numerosos testimonios confirman que las posibilidades de cuestionar, debatir o criticar las decisiones de la Dirección eran mínimas. Ello se explica tanto por la aplicación de mecanismos

25 Luis Mattini Hombres y mujeres del PRT-ERP. De Tucumán a La Tablada (La Plata: Ediciones Campana de Palo, 2007) 264.

26 Testimonio de Zenón Sánchez, Memoria Abierta, Villa Constitución, Santa Fé, 2007. El destacado es mío. 
disciplinarios como por el consentimiento de las bases. De hecho, los militantes aceptaban, con entusiasmo a veces, con resignación en otras, los dictámenes que venían desde "arriba" por diversas razones, entre ellas, la confianza irrestricta en el Partido y sus dirigentes y el convencimiento de que el contexto (marcado por la clandestinidad y la represión) justificaba el cumplimiento de medidas que no necesariamente compartían o comprendían. De este modo, si bien el Partido debía desplegar un control estricto y permanente para evitar errores o desviaciones, los compañeros debían practicar el autocontrol y la autocrítica, con el objeto de reforzar la unidad y la cohesión partidaria.

Los cuadros perretistas debían poseer y demostrar un inagotable entusiasmo y fervor revolucionario, aún frente a escenarios adversos u hostiles. Un buen revolucionario no se desanimaba frente a la derrota y mantenía intacta sus convicciones pese a todo, pues "para un revolucionario, todo es posible" 27 . Se construía así, un modelo de militante omnipotente e inquebrantable, que confiaba -ante todo y por sobre todo- en la certeza de los postulados partidarios.

Para llegar a eso, era necesario el estudio sistemático del marxismo leninismo (en particular, las obras de Marx, Engels, Lenin, Ho Chi Min, Le Duan y Vo Nguyen Giap) y de la historia del Partido. Como recuerda Liliana Callizo: "En el Frente nos pasaban mucho material partidario, en general se refería a la historia de otros pueblos: Vietnam, Camboya, China... relatos de su gente y su lucha. Eso nos servía para ver que todo era posible ${ }^{, 28}$.

Por otro lado, y siguiendo los preceptos guevaristas, se establecía que la entrega debía ser total y absoluta; así lo señala el documento elaborado por Benito Urteaga, "La formación multilateral de los cuadros", de 1974: "El cuadro debe actuar como profesional al servicio de la causa obrera, la causa de la revolución socialista (...) Su vida está dedicada por entero al servicio del movimiento revolucionario. El cuadro actúa como un hombre que piensa, reflexiona, vive en función de la Revolución",29.

En relación a este punto, Eduardo Menajovsky, recuerda su experiencia en los siguientes términos:

"Yo tenía todas las condiciones para estudiar y ser un profesional universitario, que es el paradigma de cualquier hijo de clase media de esa época, sin embargo yo no pude por problemas de conciencia conmigo mismo (...) no pude plantearme el estudio en la universidad, empecé en tres universidades y las

27 PRT-ERP (1974), "La formación multilateral de los cuadros", documento escrito por Benito Arteaga. Disponible en: http://www.cedema.org/ver.php?id=288

28 Testimonio de Liliana. Marta Diana, Mujeres Guerrilleras. Sus testimonios de la militancia de los setenta, (Buenos Aires: Planeta, 1996) 110. Los destacados son míos.

29 PRT-ERP, “La formación multilateral de los cuadros”, 5. 

dimension of revolutionary militancy. An approach to the experience of the Revolutionary Workers PartyRevolutionary People's Army and the Montoneros in Argentina in the seventies, Revista Izquierdas $\mathrm{N}^{\circ} 25$, Octubre 2015, IDEA-USACH, ISSN 0718-5049, pp. 29-53

dejé, porque me atrajo, me comió, me devoró el volcarme a la lucha política. Todo eso llevó a que nosotros dejáramos compromisos muy fuertes de vida, con nuestros hijos, nuestras familias, y asumiéramos un camino (...) de compromiso muy fuerte que por otra parte está comprometido con la formación judeocristiana que forma parte de nuestra sociedad: la entrega por el otro, el compromiso... Miles de nosotros adoptamos como proyecto de vida la entrega y el compromiso, el riesgo de perder la vida y la familia en función de esa posibilidad que la veíamos al alcance de la mano..."30.

La imagen de ser "devorado" por la lucha política es representativa de lo ocurrido con muchos otros militantes que sintieron que no podían negarse a participar en las organizaciones revolucionarias, en una suerte de "llamado de la historia" que no era posible eludir. Esto llevó a que muchos de ellos abandonaran estudios universitarios, familia de origen e hijos para poder asumir plenamente ese compromiso con la revolución.

De acuerdo al mismo documento partidario, las personas de origen proletario poseían rasgos y características más cercanos al ideal revolucionario. Señala Urteaga que los sujetos de origen proletario poseían:

"características, métodos, hábitos, formas de vida, que facilitan su desarrollo como militante revolucionario. Su espíritu de sacrificio, abnegación, disciplina, son cualidades que la propia vida en las fábricas, la producción social, el sacrificio a que se ven obligados a hacer para subsistir, los lleva en su más acelerado desarrollo como revolucionarios"31.

Este planteo ya había sido desarrollado en el documento de Luis Ortolani "Moral y Proletarización" 32 , texto publicado en 1972, cuyo objetivo era introducir a los militantes del PRT-ERP en las normas y códigos valóricos de la organización, convirtiéndose en un instrumento clave en la formación de la subjetividad militante.

Transformado en lectura obligatoria para los perretistas de todos los niveles, entregaba pautas de comportamiento orientadas a combatir la moral burguesa que se encontraba enraizada en todos los sectores de la sociedad. Siguiendo la propuesta guevarista, los

30 Testimonio de Eduardo Menajovsky, en Memoria Abierta, Buenos Aires, 2007. El destacado es mío.

31 PRT-ERP. "La formación multilateral de los cuadros"

32 Luis Ortolani, "Moral y proletarización" (1972). Políticas de la Memoria №5, (Buenos Aires 2004/5: 18). Originalmente, el texto fue publicado con el seudónimo de Luis Parra en La gaviota blindada, $\mathrm{n}^{\circ}$, Rawson. El documento desarrolla los principales postulados de la proletarización, pese a que esta práctica se había comenzado a implementar con anterioridad. Asimismo, es preciso señalar que la proletarización no fue exclusiva, ni tampoco una creación, de la izquierda revolucionaria. 
perretistas debían enfrentar no solo al aparato represivo del Estado burgués, sino también a una moral burguesa que era preciso destruir. El núcleo duro de esa moral era individualismo, defecto que se transmitía por los padres a sus hijos a partir del "primer trago de leche materna",33.

De acuerdo al texto, las organizaciones revolucionarias no estaban a salvo del individualismo, el que se manifestaba a través de una serie de conductas entre las que se menciona el subjetivismo, la búsqueda de prestigio, el temor por sí mismo y el liberalismo. Estas prácticas debían ser combatidas a través de la constante crítica y autocrítica, una suerte de vigilancia cotidiana orientada a evitar ciertas conductas que podían ser catalogadas como burguesas. Los revolucionarios debían desintegrar la personalidad individualista y volverla a integrar, esta vez sobre los pilares de los valores proletarios; y, con ese fin, se puso en práctica la llamada "proletarización", entendida como el "compartir la práctica social de la clase obrera, su modo de vida y su trabajo"34.

Este proceso de transformación suponía el cumplimiento estricto de normas que respondían al siguiente mandato: los militantes obreros debían seguir siéndolo, mientras que los militantes de origen burgués o pequeño burgués debían proletarizarse, con el objeto de internalizar las virtudes del pueblo, a saber "humildad, sencillez, paciencia, espíritu de sacrificio, amplitud de criterios, decisión, tenacidad, deseos de aprender, generosidad, amor al prójimo"35. Para ello, los militantes no proletarios debían ingresar a trabajar en fábricas para sumergirse en la realidad obrera y, desde ahí, y siendo como uno más de ellos, ganar adeptos para el proyecto partidario. Como señala el mismo texto, "El que tiene una práctica social de obrero tenderá a tener una conciencia de obrero. El que tiene una práctica de policía tendrá una conciencia de policía; he aquí la primera clave de la cuestión...”36.

De acuerdo a este planteo, se entendía que en el seno del proletariado la formación de la conciencia de clase era expedita (si no automática). Por lo tanto, los militantes de clases medias debían realizar una suerte de regeneración y reestructuración identitaria para convertirse en auténticos revolucionarios.

Es preciso recordar que la proletarización fue parte de una constante inquietud partidaria respecto a la composición social de los miembros del PRT, más precisamente, respecto a la escasa presencia de obreros en sus filas, cifra que de acuerdo al mismo Santucho, no

33 Ortolani, 18.

34 Ortolani, 21.

35 Ortolani, 20.

36 Ortolani, 19. 
sobrepasaba el $30 \%$ del total ${ }^{37}$. Como respuesta a ello, el Partido desplegó enormes esfuerzos orientados a fortalecer su inserción en las fábricas con el objeto de aumentar su penetración orgánica en el proletariado.

La puesta en marcha de la política de proletarización tuvo resultados disímiles. Mientras Daniel de Santis, ex miembro del Comité Central del Partido, se proletarizó y producto de ello fue elegido delegado por los obreros de la Propulsora Siderúrgica, otros militantes no lograron insertarse exitosamente en una realidad que -en muchos sentidos- se alejaba de la imagen que el Partido había construido sobre el mundo obrero. Justamente, Pablo Pozzi señala que las prácticas culturales de los obreros argentinos no coincidían con las definiciones perretistas sobre la moral proletaria. La organización -de acuerdo a su perspectiva- idealizó a la clase obrera atribuyendo al proletariado todas las virtudes humanas, obrerismo aportado por los elementos trotskistas del Partido. De este modo, mientras los militantes de origen proletario asumían que el ascenso social era algo posible y deseable, la organización les señalaba que, para ser buenos revolucionarios, debían seguir siendo obreros.

Ahora bien, el proceso de asimilarse al obrero, o más bien, a la imagen del obrero construida por el PRT-ERP, no fue una tarea sencilla. Adoptar los modos de hablar, las formas de vestir y la apariencia corporal del sujeto histórico al que se decía representar resultó ser más complejo de lo esperado. Daniel De Santis, lo narra así:

"Consigo un trabajo en la construcción con un arquitecto amigo que estaba dirigiendo una obra, bueno, me toman y cuando llego ahí "qué hago acá, cómo me comporto como un obrero"... Llego a la obra y nadie decía nada, llega el capataz y a mí me parece que lo más normal era preguntarle cuanto me iba a pagar y me dice que me vaya... Yo me puse a llorar, que no que por favor, que necesito trabajar y me dejó. Eso me aleccionó en el hecho de que me tuve que humillar por un motivo político y me puse a pensar lo que sufre un trabajador de verdad (...). A las tres de la tarde me descomponía de cansancio ya no aguantaba más, y tuve que aguantar a fuerza de conciencia, porque si no aguanto, no me podía proletarizar..."

Más tarde, la experiencia de este mismo militante en Propulsora Siderúrgica puso en evidencia las contradicciones anidadas en la propuesta de proletarización. Con el objeto de asimilarse a sus compañeros y de cumplir el mandato partidario de adoptar la forma de vida proletaria, compartió con sus colegas después de la jornada laboral; esos momentos de

37 De acuerdo a Vera Carnovale, Pablo Pozzi es más generoso con las cifras, afirmando que el 45\% de los militantes perretistas eran obreros fabriles y rurales., Vera Carnovale, Los combatientes (Buenos Aires: Siglo XXI, 2011).

38 Memoria Abierta. Testimonio de Daniel Héctor De Santis Gonnet, Buenos Aires, 2008. 

dimension of revolutionary militancy. An approach to the experience of the Revolutionary Workers PartyRevolutionary People's Army and the Montoneros in Argentina in the seventies, Revista Izquierdas $\mathrm{N}^{\circ} 25$, Octubre 2015, IDEA-USACH, ISSN 0718-5049, pp. 29-53

socialización incluían la visita frecuente a cabarets. Cuando De Santis informó esto a su superior, fue duramente reprendido ${ }^{39}$.

Como señala la historiadora argentina Vera Carnovale, la proletarización fue una de las formas que adoptó el mandato del sacrificio y la renuncia. Al mismo tiempo, funcionó como un mecanismo de disciplinamiento y homogenización de la militancia; prueba de ello es que en algunos casos fue usada a modo de castigo para quienes cometían alguna falta o desvío. Ahora bien, es preciso considerar que la aplicación de las normas partidarias expuestas en "Moral y Proletarización" fue flexible y diversa, y que la internalización de esos mandatos no fue automática ni mecánica.

Si nos detenemos en el caso de Montoneros, es posible advertir que la prensa partidaria publicó numerosos reportajes y notas para rendir homenaje a compañeros asesinados cuyo ejemplo debía servir de modelo al conjunto de la militancia. Un ejemplo de ello es la nota titulada El mandato político de Fernando Abal Medina ${ }^{40}$, texto que recuerda la trayectoria militante de una de las figuras más emblemáticas del movimiento, dada su participación en el asesinato de Aramburu. En relación a su formación ideológica, el texto destaca:

"su formación nacionalista le había permitido la comprensión del pasado argentino y el rescate de una línea histórica de resistencia nacional representada por las montoneras del siglo XIX. También eran claras en él la influencia de John William Cooke, al remarcar la potencialidad revolucionaria del peronismo, y de Juan García Elorrio, con el aporte del cristianismo camilista, forma de acceder al vasto mundo guevariano" 41 .

Esta heterodoxia ideológica fue uno de los rasgos que distinguió a Montoneros de las otras organizaciones revolucionarias analizadas. Al mismo tiempo, y en un sentido similar al tono anti-intelectual de algunos enunciados perretistas, el texto afirma:

"En buena hora, los precursores, los militantes heroicos, dieron preeminencia al momento práctico, antes que a la caracterización teórica. Es lo que distingue un hecho revolucionario, de una intelectualización revolucionaria. A nuestro país, le sobran lectores de la realidad. El mandato transformador de Fernando, es una exigencia ineludible" ${ }^{, 42}$.

\footnotetext{
${ }^{39}$ Memoria Abierta, Testimonio de Daniel Héctor De Santis Gonnet, Buenos Aires, 2008

40 Montoneros (julio 1973), Militancia Peronista para la Liberación, 13. Abal Medina murió en Buenos Aires en un enfrentamiento con la policía junto a Carlos Gustavo Ramus. El día de su muerte fue conmemorado como el Día de Joven Montonero.

${ }^{41}$ Militancia Política para la Liberación ${ }^{\circ}$ 13. Disponible en: http://www.elortiba.org/docmon.html 42 Militancia Política para la Liberación $n^{\circ}$ 13. Disponible en: http://www.elortiba.org/docmon.html
} 
En el caso de esta organización es preciso destacar que en las estructuras de base "el origen y la identidad política de la militancia era peronista" ${ }^{43}$. De esta manera, las influencias de la Revolución Cubana, las luchas tercermundistas de Argelia y Vietnam, la Teología de la Liberación, así como las lecturas de los clásicos marxistas o las obras de Franz Fanon, ocupan un lugar más periférico en el conjunto de razones que motivaron a muchos jóvenes a sumarse a la organización. Lo realmente decisivo fue la experiencia en organizaciones gremiales y/o territoriales en las que el ideario peronista era un núcleo articulador, tanto en términos políticos como identitarios. Como señala el historiador Javier Salcedo en una investigación sobre los militantes del barrio de Moreno,

"El único que pretendía formarse teóricamente por su cuenta, más allá de las bajadas de línea, era cuestionado con bromas de distinta magnitud entre sus compañeros de militancia. La ética revolucionaria que llevaba a la construcción del hombre nuevo no regía mayoritariamente del mismo modo que entre los cuadros que bajaban de la Organización. Prácticas políticas y gremiales un tanto ajenas a esta construcción ética, impregnadas de la picardía de quienes habían vivido otra realidad, estaban demasiado enraizadas en algunos de los militantes, lo que hacía que fueran descalificados, según las circunstancias, por la Conducción o la organización. La socialización de propiedades y salarios, cuando fue propuesta a quienes tenían alguno, provocó más espanto que comprensión”.

Apelando a figuras y personajes del peronismo, los militantes asumían como propia la tarea de luchar por el socialismo nacional. Estableciendo una línea de continuidad entre la Resistencia peronista de la década del cincuenta y el proyecto montonero de los años setenta, la organización se situaba a sí misma como la legítima heredera de las luchas históricas de los sectores populares de Argentina. Esa densidad histórica fortalecía la identificación de los militantes con la organización y animaba su entrega total a ella. De acuerdo a la ex militante Adriana Robles:

"Recuerdo cómo y cuánto me conmovían las historias de esa Resistencia Peronista que ignoré porque a mi casa no entraba. Felipe Vallese, Martins y Centeno, Maestre y Misetich, los montoneros buscados y luego muertos en combate: Fernando Abal Medina, Gustavo Ramus"44.

La experiencia política de Robles es representativa de las trayectorias de muchos otros jóvenes montoneros. Ella se acercó a la militancia durante la secundaria; desde entonces adquirió conductas y rasgos que la transformaron en la "rara del grupo". A diferencia de las

43 Javier Salcedo, Los montoneros del barrio, (Editorial de la Universidad Nacional Tres de Febrero: Caseros, 2011) 58.

44 Robles, 52. 
otras chicas de su edad era seria, preocupada de asuntos importantes y con sentimientos de superioridad respecto de las demás. Como ella misma describe: "la revolución me distinguía"45. Al igual que en los casos anteriores, el proceso de formación política fue transformando a los militantes en sujetos diferentes; esa diferencia era percibida por los otros y destacada por los propios militantes como un elemento de distinción.

Asimismo, los intereses personales debían ser funcionales al proyecto revolucionario; de no ser así, debían ser postergados o simplemente cancelados. Cuando Adriana ingresó a la Universidad a estudiar Letras, sus compañeros se opusieron, como recuerda:

"Siguiendo mi amor por la poesía y la lectura, me decidí por Letras (...) el verdadero gran obstáculo fue la visión que mis compañeros tenían sobre mi elección (...) como la mía no era una carrera prioritaria ni demasiado útil para nuestra acción revolucionaria, debía optar por una actividad territorial en una estructura militar. (...) Asumí con total claridad y conciencia ese costo (...) si que yo estudiara letras no le servía a esa revolución, entonces no tenía sentido hacerlo. Era más necesaria una presencia en otros ámbitos pero en mi historia fue durante mucho tiempo, un pequeño dolor" 46 .

Tanto el PRT-ERP como Montoneros pusieron en práctica políticas que asignaron a la cuestión militar un lugar central dentro de sus lineamientos políticos. Un documento que permite analizar las conductas consideradas ejemplares, es la carta que Rodolfo Walsh dirigió a sus amigos refiriéndose a la muerte de su hija María Victoria en un enfrentamiento con el Ejército en el mes de septiembre de 1976. La militante montonera (que se encontraba acompañada de su pequeña hija de poco más de un año de vida) decidió no entregarse con vida y se suicidó antes de ser capturada, política que había sido adoptada por la organización para evitar que los militantes que fueran apresados pudiesen entregar información al momento de ser torturados.

Recordando a su hija, Rodolfo Walsh escribió:

"Mi hija no estaba dispuesta a entregarse con vida. Era una decisión madurada, razonada (...) Sabía perfectamente que en una guerra de esas características, el pecado no era no hablar, sino caer (...)

En el tiempo transcurrido he reflexionado sobre esa muerte. Me he preguntado si mi hija, si todos los que mueren como ella, tenían otro camino. La respuesta brota de lo más profundo de mi corazón y quiero que mis amigos la conozcan. Vicki pudo elegir otros caminos que eran distintos sin ser deshonrosos, pero el 

dimension of revolutionary militancy. An approach to the experience of the Revolutionary Workers PartyRevolutionary People's Army and the Montoneros in Argentina in the seventies, Revista Izquierdas $\mathrm{N}^{\circ} 25$, Octubre 2015, IDEA-USACH, ISSN 0718-5049, pp. 29-53

que eligió era el más justo, el más generoso, el más razonado. Su lúcida muerte es una síntesis de su corta, hermosa vida. No vivió para ella: vivió para otros, y esos otros son millones. Su muerte sí, su muerte fue gloriosamente suya, y en ese orgullo me afirmo y soy yo quien renace de ella"47.

En las palabras de Walsh es posible advertir diversos elementos que fueron parte de la cultura política montonera: la exaltación y glorificación de la muerte en combate; el sacrificio por los otros como la máxima expresión de la consecuencia revolucionaria; la muerte como una experiencia fecunda que permite que los otros renazcan y den continuidad a la lucha. Asimismo, pone en valor la muerte elegida (el suicidio), una muerte "gloriosamente suya", en oposición a la muerte robada o arrebatada por los represores (ser asesinado). Se trata, en definitiva, de una muerte heroica, la muerte de los fuertes, la muerte de los mejores.

En "Evita Montonera" de abril y mayo de 1976, se publicó una nota titulada "No quiero entregarme viva", texto en el que se puede leer el testimonio de un militante que fue emboscado junto a su compañera. En medio del combate ella es herida y le ruega a su pareja que la ejecute para no entregarse con vida al enemigo. El relato del militante señala: "Su seguridad y amor por el pueblo y la Organización demostrado en su práctica diaria y en ese combate desigual, no me hacen dudar de cumplir con lo que me pide". Junto al breve testimonio, hay una nota explicativa que celebra la consecuencia de ambos militantes.

"Al tomar estas decisiones los compañeros demuestran no solo el amor al proyecto revolucionario y a la Organización que lo encarna, sino una profunda y racional comprensión de la clase de enemigos que enfrentamos (...) Las alternativas son la victoria o la muerte.

El compañero $\mathrm{N}$ fue promovido a oficial y condecorado por su acción destacada en el cumplimiento del deber revolucionario. La compañera Moni demostró con su actitud frente al enemigo suficiente comprensión política y solidez ideológica como para integrar nuestra Organización (nuestro Partido) como miembro pleno. Ese carácter le fue conferido por el Consejo nacional, como homenaje a su memoria" ${ }^{\prime 4}$.

La historia -real o ficticia- de los dos militantes, tiene un sentido ejemplificador y fortalece con dramatismo el mandato sacrificial de la guerrilla en el escenario postgolpe. El relato

47 Rodolfo Walsh, "Carta a mis amigos". Cuadernos de Militancia no 4, (1976). Disponible en: http://www.elhistoriador.com.ar/documentos/dictadura/rodolfo_walsh_y_la_muerte_de_su_hija_maria_victor ia.php. Los destacados son míos.

${ }_{48}$ Montoneros (abril-mayo de 1976), Evita Montonera, 36. 
describe una escena extrema pero cotidiana para los militantes de la organización: el enfrentamiento armado con los organismos represivos, y les señala el camino a seguir en una situación que estaba dentro de los escenarios posibles.

Al mismo tiempo, el relato condensa diversos elementos que son centrales en la configuración de la cultura montonera: el mandato sacrificial, el heroísmo, la obediencia, la conciencia de ser sujetos excepcionales. En este punto, vale la pena detenerse en las reflexiones del crítico búlgaro-francés Tzvetan Todorov, quien en su libro "Frente al límite" analiza la figura del héroe, afirmando que está unida a la muerte. Señala este autor:

"La elección es entre la vida sin gloria y la muerte en la gloria. El héroe escoge la muerte no porque la aprecie en sí misma (no es un ser mórbido) sino porque es un absoluto: eso mismo que la vida no es (la simetría de los términos es engañosa). La muerte está inscrita en el destino del héroe. El héroe es en todos esos aspectos, diferente de los demás hombres. Dotado de un poder excepcional, se encuentra ya al margen de las personas ordinarias; habiendo preferido la muerte sobre la vida, se separa aún más de ellas" $" 49$.

De este modo, no se valoraba el suicidio en sí mismo sino en tanto acto que era la máxima expresión de la voluntad y el heroísmo. De hecho, muchos militantes señalan que el suicido era la única forma de evitar la delación y la traición, un acto de generosidad hacia los otros que suponía la clausura literal del propio yo.

Por otro lado y al igual que el PRT-ERP, Montoneros era una organización jerárquica con un verticalismo creciente a medida de que la militarización interna se intensificaba. Las posibilidades de disentir eran mínimas y quienes se atrevían a hacerlo, o eran sancionados o terminaban fuera de la organización.

Además de los numerosos testimonios en los que aparecen mencionados con bastante frecuencia estos procesos de encuadramiento político y los sucesivos abandonos que ello implicaba, hay documentos internos que permiten analizar la cultura política de esta organización. Uno de ellos es el "Manual de instrucciones de las milicias montoneras",50, cuya primera edición es del año 1975 y que estaba dirigido a quienes estaban a cargo de la formación de futuros militantes y milicianos, como parte de una política de incorporación masiva de nuevos integrantes a la organización. La formación consideraba el manejo de diversas materias: realidad política nacional e internacional, estructura organizativa y política partidaria, nociones básicas sobre uso de armamento y disciplina militar. Este texto fue elaborado en un momento en que las acciones armadas se transformaron en la principal

49 Tzvetan Todorov, Frente al límite, (Madrid, Siglo XXI, 2009) 54.

50 Montoneros (1975), Manual de instrucciones de las milicias montoneras. Citado por Alejandra Oberti, p. 131. 
forma de hacer política, lo que supuso incrementar los niveles de centralización en la toma de decisiones y fortalecer los mecanismos disciplinarios; expresión de ello son los numerosos juicios aplicados a militantes que infringieron las normas partidarias.

En relación a este punto, la investigadora argentina Laura Lenci señala que la justicia revolucionaria tuvo como objeto privilegiado a los propios militantes de la organización ${ }^{51}$. Tanto las "Disposiciones sobre la Justicia Penal Revolucionaria" (en adelante DJPR) de 1972, como el "Código de Justicia Penal Revolucionario" (en adelante CJPR) de 1975 estaban orientados a disciplinar al conjunto de la militancia. El primero de estos cuerpos normativos fue redactado y difundido a fines de 1972, año en que la organización alcanzó gran visibilidad pública y un crecimiento significativo.

El contexto de producción del CJPR es completamente diferente: luego del breve gobierno de Cámpora (momento en que la organización se acercó a la institucionalidad estatal) devino una crisis de Montoneros con sectores de derecha del peronismo que culminó con el quiebre definitivo con Perón en mayo de 1974. Más tarde, la creciente represión y la clandestinidad $^{52}$ afectarían dramáticamente trabajo político y de masas de la organización, al mismo tiempo que se agudizó la militarización y la burocratización interna. Era un momento en que había importantes discusiones y debates acerca de las políticas adoptadas por la conducción montonera, de modo que se esperaba que el incremento de la disciplina asegurara la cohesión partidaria.

Esas normativas establecían las conductas que los militantes debían adoptar en el caso de ser apresados y además, asignaban un lugar importante al tema de la obediencia y la disciplina interna, sancionando la insubordinación (desacato de órdenes) y la conspiración (realización de actividades orientadas a dividir la organización). En relación a los aspectos punitivos de ambos cuerpos, están considerados el confinamiento, el destierro, la degradación, la prisión, la expulsión y fusilamiento. En el primer documento, la pena de muerte estaba reservada para los casos de traición, deserción en combate, delación y confesión, mientras que el segundo sumaba a estos delitos, la insubordinación, conspiración, defraudación, abuso de autoridad, evasión, encubrimiento, instigamiento y complicidad.

51 Lenci afirma que la aplicación de la Justicia revolucionaria fue, en efecto, anterior a la promulgación de estos códigos. De acuerdo a esta autora, el primer ajusticiamiento interno es de 1971.

52 El pase a la clandestinidad de Montoneros provocó malestar en sectores de la organización, ya que muchos militantes no tenían los recursos materiales para aplicar esa orden y la Conducción -pese a la enorme cantidad de recursos obtenidos a partir del secuestro de los hermanos Born-, no entregó el dinero suficiente para asegurar la seguridad de sus militantes. Julieta Bartoletti, Montoneros: de la movilización a la Organización. Un caso paradigmático de militarización (Tesis para optar al grado de Doctor en Ciencia Política: Universidad Nacional de San Martín, 2010) 622. 
Si bien el escenario político solo permitió que se llevaran a cabo un número limitado de juicios (y que aún en esos casos los códigos normativos se aplicaran solo parcialmente), Lenci $^{53}$ afirma que el análisis de estos textos permite establecer que la militarización y burocratización montonera expresa la agudización de rasgos que eran parte del proyecto revolucionario desde sus comienzos, y no una desviación o tergiversación de los mismos. Señala la autora:

"Esos contenidos culturales de la política, que casi todos los autores acuerdan con que llevaron a la derrota de la organización, no aparecieron en los momentos de crisis. En los momentos de crisis, y sobre todo a partir de fines de 1975, esos contenidos se exasperaron, se hicieron más evidentes y más incomprensibles debido al terrible endurecimiento de la represión y el aislamiento de la organización. Pero estaban allí desde mucho antes, en el corazón del proyecto político -como lo demuestra la existencia de esas hasta ahora desconocidas Disposiciones sobre la Justicia Penal Revolucionaria de $1972 " .54$

Ahora bien, y como advierte Alejandra Oberti, el análisis de estos textos ilumina no solo la dimensión más normativa y disciplinante de la militancia, sino también las transgresiones, disensos y desacatos que hicieron necesaria la codificación de la justicia revolucionaria, aspecto que no debe ser desatendido.

\section{A modo de conclusión.}

La experiencia de la militancia revolucionaria fue mucho más que la adhesión racional a una ideología o a una organización determinada. La organización era el espacio de la lucha política, pero también el ámbito del amor y los afectos, de modo que la adhesión y pertenencia era tan racional como emocional; ahí, se construían lazos políticos para también poderosos vínculos de amistad y de pareja. La crianza de los hijos tampoco estuvo ajena a las regulaciones y mandatos de las organizaciones, pues el cuidado cotidiano de los pequeños era considerado parte de las tareas militantes, tan relevantes como cualquier otra tarea político-militar. Se trataba de educar a las futuras generaciones en los valores del socialismo y la revolución y para ello era preciso que los hijos de los revolucionarios compartieran todos los aspectos de la vida de sus padres, incluyendo sus riesgos y peligros.

53 María Laura Lenci, “Justicia, política y violencia. Un análisis de los cuerpos normativos montoneros 19721975". Ponencia presentada en la Jornada académica Partidos Armados en la Argentina de los años 70 (UNSAM: 2008).

54 Lenci: 33. 
Tanto Montoneros como el PRT-ERP exigían a sus integrantes una entrega total y absoluta a la causa que perseguían, de modo tal que la militancia se constituía en una forma de ser y estar en mundo. La adhesión emocional organización explica por qué muchos militantes, aun teniendo diferencias políticas con las decisiones adoptadas por sus dirigentes, se mantuvieron fieles a la línea partidaria, acatando sus órdenes e, incluso, aceptando las sanciones que se les aplicaban. Tal como señala la ex militante montonera Adriana Robles, "La forma en que se fueron planteando esas diferencias fueron distintas en cada caso pero ambas terminaron con mi aceptación subordinada de los cargos y la sanción. No toleraba la idea de dejar de pertenecer a esa gesta revolucionaria",55.

Por último, un rasgo común a las dos organizaciones acá observadas es percibirse a sí mismas como únicas y excepcionales. Los militantes creían ser los mejores, los más preparados, valientes y puros. Había también un sentido de omnipotencia, grandeza e invencibilidad, que los situaba por sobre el común de los hombres y mujeres que decían representar. Es posible que en Montoneros este rasgo fuera más visible, dado la formación religiosa de muchos de sus dirigentes y militantes. Por otro parte, la noción de vanguardia leninista, el modelo de Hombre Nuevo guevarista y la noción de sacrificio cristiana, estaban estrechamente articuladas. Como señala Robles:

“Éramos la expresión más pura y legítima del pueblo peronista y estábamos dispuestos a dar la vida por él (...) El sentimiento de orfandad que dejó la muerte de Perón caló muy profundamente en nuestro espíritu militante creando nuestra omnipotencia como contrapeso. Y creo que así fue como cada uno de nosotros se fue convirtiendo en más y más para los otros compañeros. No había nada más potente que nuestra militancia ni nadie que nos pudiera quebrar. Todos éramos gigantes ${ }^{, 56}$.

Recibido: 3 febrero 2015

Aceptado: 7 mayo 2015

55 Robles, 76.

56 Robles, 70. El destacado es mío. 


\section{Referencias}

Julián Bastías, "A propósito del MIR chileno. Un intento de psicología partidaria. Representaciones sociales y subsistemas ideológicos como factores de inhibición en la crítica de los militantes", Psicología de la acción política. Orlando D'Adamo (Buenos Aires: Paidós)

Julieta Bartoletti, Montoneros: de la movilización a la Organización. Un caso paradigmático de militarización (Tesis para optar al grado de Doctor en Ciencia Política: Universidad Nacional de San Martín, 2010).

Pilar Calveiro, Poder y desaparición, (Buenos Aires: Colihue, 1998).

Vera Carnovale, Los combatientes (Buenos Aires: Siglo XXI, 2011).

Isabella Cosse, Pareja, sexualidad y familia en los años sesenta (Buenos Aires, Siglo Veintiuno Editores, 2010).

Eduardo Devés Valdés, El pensamiento latinoamericano en el siglo XX. Desde la CEPAL al neoliberalismo (1950-1990) (Santiago: Biblos, 2003).

Marta Diana, Mujeres Guerrilleras. Sus testimonios de la militancia de los setenta, (Buenos Aires: Planeta, 1996).

Eric Hobsbawm, Historia del Siglo XX, (Buenos Aires: Planeta/Crítica, 2002).

Norbert Lechner, Los Patios interiores de la Democracia: Subjetividad y Política, (Santiago: FLACSO, 1988)

Norbert Lechner, La Conflictiva y nunca acabada construcción del orden deseado (Madrid: Siglo XXI, 1986).

Michael Lowy, El marxismo en América Latina, Santiago (Santiago: Lom, 2007)

Luis Mattini Hombres y mujeres del PRT-ERP. De Tucumán a La Tablada (La Plata: Ediciones Campana de Palo, 2007)

Alejandra Oberti, "Género, política y violencia. Vida cotidiana y militancia en las décadas del sesenta y setenta". Tesis para optar por el título de Doctora de la Universidad de Buenos Aires en Ciencias Sociales, Facultad de Ciencias Sociales (UBA: Mimeo inédito, 2011). 
Pablo Pozzi, "Por las sendas argentinas..." El PRT-ERP, la guerrilla marxista (Buenos Aires: Ediciones Imago Mundi, 2004).

Adriana Robles, Perejiles. Los otros Montoneros, (Buenos Aires, Colihue, 2005)

María Olga Ruiz, Historias y memorias de traición. Subjetividad revolucionaria, mandatos militantes y traición en el Partido Revolucionario de los Trabajadores-Ejército Revolucionario del Pueblo (PRT-ERP), Montoneros y el Movimiento de Izquierda Revolucionaria (MIR) en las décadas del sesenta y setenta. (Tesis para optar al grado de Doctora en Estudios Latinoamericanos: Universidad de Chile, 2014)

Javier Salcedo, Los montoneros del barrio, (Editorial de la Universidad Nacional Tres de Febrero: Caseros, 2011).

Horacio Tarcus, "La secta política Ensayo acerca de la pervivencia de lo sagrado en la modernidad", Revista El Rodaballo Vol. 9. (Buenos Aires, 1998/1999)

Tzvetan Todorov, Frente al límite, (Madrid, Siglo XXI, 2009).

Enzo Traverso, El pasado, instrucciones de uso. Historia, memoria, política (Madrid: Editorial Marcial Pons, 2007)

María Cristina Tortti, "La nueva historia en la historia reciente de Argentina", Revista de Estudios Sociales No 3 (La Plata: Prometeo, 2005).

Raymond Williams, Marxismo y literatura (Buenos Aires: Editorial Las Cuarenta, 2009). 